\title{
O Moodle como ferramenta de acompanhamento pedagógico na Educação Básica: um relato de experiência
}

\author{
Clarissa Bezerra de Melo Pereira Nunes ${ }^{1}$, Apuena Vieira Gomes ${ }^{1}$, Ismenia \\ Blavatsky de Magalhães ${ }^{1}$
}

${ }^{1}$ Instituto Metrópole Digital (IMD) - Universidade Federal do Rio Grande do Norte (UFRN) - Av. Senador Salgado Filho, 3000, CEP 59.078.970 - Natal - RN - Brasil.

klanunes@ufrn.edu.br, (apuena, ismenia) dimd.ufrn.br

\begin{abstract}
Studies on innovative forms of school monitoring that use digital tools are still recent in Brazil, especially when related to Basic Education. Understanding what students are understanding about the contents and concepts worked in the classroom is still a challenge. In this sense, this work seeks to report the experience of using VLE Moodle as an additional tool to the classroom by a teacher from Middle School, as a way of monitoring the way in which students appropriate what is worked on. Such practice has proved to be quite effective, mainly because it allows educational feedback in real time to the pedagogical coordination, teachers and students.
\end{abstract}

Resumo: Estudos sobre formas inovadoras de acompanhamento escolar que utilizem ferramentas digitais ainda são recentes no Brasil, sobretudo quando relacionados à Educação Básica. Entender o que os alunos estão compreendendo sobre os conteúdos e conceitos trabalhados em sala de aula ainda é um desafio. Neste sentido, este trabalho busca relatar a experiência de uso do AVA Moodle como uma ferramenta adicional à sala de aula por uma professora do Ensino Fundamental 2, como uma forma de acompanhar o modo no qual os alunos se apropriam do que é trabalhado. Tal prática tem se mostrando bastante eficaz, principalmente por possibilitar um feedback educacional em tempo real a coordenação pedagógica, professores e alunos.

\section{Introdução}

De acordo com Melo Filho et al. (2008), agregar tecnologias para o desenvolvimento da prática docente é um dos caminhos para a construção de novas metodologias educativas. $\mathrm{O}$ aumento exponencial da informação, em virtude da adoção de Tecnologias Digitais de Informação e Comunicação (TIDCs) como os Ambientes Virtuais de Aprendizagem (AVAs), têm conduzido a novas organizações de trabalho, como forma de proporcionar e facilitar diversas formas de interação entre discentes, conteúdos e docentes. Nunes (2019) acrescenta que é imprescindível munir os educadores de conhecimento não só sobre como utilizar as TDICs, mas também sobre como e porquê utilizá-las em prol do desenvolvimento de habilidades, da construção do saber e da gestão da aprendizagem.

Uma vez que estudos sobre formas inovadoras de avaliação e acompanhamento escolar relacionados ao uso de TDICs ainda são recentes no Brasil, são necessárias pesquisas que busquem identificar, analisar e apresentar como tais instrumentos vêm sendo utilizados. Dessa forma, este trabalho busca relatar a experiência de uso do AVA 
Moodle $^{1}$ como uma ferramenta adicional à sala de aula por uma professora do Ensino Fundamental 2, como uma forma de responder à questão "como acompanhar o entendimento dos alunos sobre o conhecimento trabalho em sala?" Para tal, este trabalho está estruturado em quatro seções: esta Introdução, onde foi exposto o problema; Trabalhos Relacionados, que tratam sobre experiências similares à vivenciada; Relato de Experiência, onde é detalhado como foi feito o uso do Moodle na prática pedagógica; Resultados e Discussão, e Considerações Finais.

\section{Trabalhos Relacionados}

O uso do AVA para o acompanhamento pedagógico apresenta-se como um tema sobre o qual poucos trabalhos têm sido produzidos. Uma pesquisa realizada no Portal $\mathrm{CEIE}^{2}$, buscando trabalhos relacionados retornou oito publicações produzidas entre os anos de 2001 e 2019, dos quais três apresentaram contribuições para a educação básica.

Nascimento e Oeiras (2008) tratam sobre o uso do Moodle para a realização de competições escolares aplicadas ao ensino fundamental, médio e superior, o que são esforços pontuais, uma vez que as atividades selecionadas e os resultados obtidos, apesar de relatados terem sido positivos, não avaliam como os alunos utilizaram o AVA. Barbosa, Oliveira e Penna (2015) apresentam um trabalho sobre a usabilidade do Moodle na perspectiva de alunos que cursam o ensino fundamental, apontando para problemas de utilização que podem dificultar o uso dessa plataforma por esse perfil de usuários. Por fim, Kaminski e Boscarioli (2016) relatam uma experiência do uso da Plataforma Moodle pelos alunos do $5^{\circ}$ Ano do Ensino Fundamental como estímulo aos hábitos de estudo, desenvolvendo a autonomia dos estudantes e colaborando na melhora de seu desempenho.

No geral, os trabalhos aqui relacionados focam predominantemente nos profissionais da educação ou na usabilidade dos AVAs, não apresentando investigação ou resultados com relação à aprendizagem dos alunos, que é o objetivo deste estudo.

\section{Relato de experiência}

Este trabalho aproveita a experiência de uma pesquisadora a partir do ensino da Língua Inglesa em um Programa Bilíngue, de uma escola privada localizada em Natal/RN, para turmas de $6^{\circ}$ ano do Ensino Fundamental desde 2016. As aulas são ministradas cinco vezes por semana e acontecem na língua-alvo, representando um desafio adicional à prática pedagógica. Assim, é imprescindível a adoção de estratégias para acompanhar como os alunos se apropriam dos conteúdos e como desenvolvem habilidades comunicativas à medida em que os objetos do conhecimento são trabalhados.

Em 2016 foi iniciada a adoção de um AVA Moodle como uma ferramenta para centralizar e disponibilizar materiais (listas de exercício, slides e outros) para os alunos. Em 2018, buscando acompanhar como os seus alunos entendiam cada conteúdo trabalhado, a pesquisadora passou a elaborar atividades no AVA em substituição aos populares "vistos" (processos de checagem de cadernos e livros dos alunos, para acompanhar quais atividades estão ali apresentadas, sem precisar exatamente quando as mesmas foram realizadas ou por quem).

\footnotetext{
${ }^{1}$ www.moodle.org

2 https://www.br-ie.org/pub/index.php/index
} 
Com esta nova prática, criou-se uma nova metodologia pedagógica ao se explorar e agregar funcionalidades do AVA ao planejamento e às atividades semanais dos alunos. À medida em que cada conteúdo era introduzido, trabalhado, exercitado e discutido com os discentes, as atividades passavam a ser disponibilizadas para os alunos as realizarem no AVA. Por entender que estudar é um exercício que leva ao aprendizado, combinou-se que cada atividade ficaria disponível para realização no AVA por um período mínimo de 10 dias, e que os alunos teriam três tentativas - das quais prevaleceria a maior nota para compor a avaliação processual preconizada pela escola como parte do processo educacional, trimestralmente. Os alunos foram, dessa forma, orientados sobre qual o melhor momento para executar cada tentativa.

A primeira tentativa foi realizada ainda em sala de aula. Requisitou-se aos alunos que anotassem as perguntas e respostas que o sistema selecionou aleatoriamente, de um banco de questões organizado e categorizado por assunto, tipo de questão e nível de complexidade. Esse momento foi especificamente planejado para que os educandos, com o auxílio da professora, pudessem discutir suas dificuldades de interpretação e de conteúdo sobre o assunto a ser avaliado. Realizar uma primeira tentativa em sala de aula permitiu à docente verificar o entendimento, a nível individual e coletivo, relacionado aos tipos de questões e enunciados presentes nas atividades.

Ao final de cada tentativa, os alunos receberam uma nota gerada automaticamente pelo AVA, a qual funcionou como feedback para balizar o quanto o aluno compreendeu em relação ao assunto, para que buscasse melhorar ou manter o seu desempenho. Os alunos foram orientados a revisitar os assuntos e estudar os assuntos antes de realizar uma segunda tentativa, em cinco dias. Caso o aproveitamento deste segundo momento tivesse sido similar ou inferior ao anterior, sugeria-se procurar a professora para identificar onde residiam as suas dificuldades, a fim de que pudessem melhorar o entendimento e compreensão acerca do objeto de aprendizagem.

Por fim, a terceira tentativa foi indicada para quando a atividade estivesse perto de seu encerramento, no $9^{\circ}$ ou $10^{\circ}$ dia, também com o foco no feedback qualitativo (quantidade de acertos) ao estudante e sua família sobre o nível de entendimento concernente ao objeto do conhecimento que estava sendo testado. Ao final do período de feitura das atividades, o sistema permitiu aos alunos revisar as suas tentativas (feedback qualitativo), possibilitando checar quais os seus erros, acertos e quais as chaves de resposta para cada questão.

\section{Resultados e Discussão}

Quando as tentativas disponíveis para cada atividade foram realizadas tal como recomendadas, observou-se um impacto positivo no rendimento acadêmico dos alunos. Na Figura 01 estão representadas a quantidade de tentativas realizadas na Atividade 05 (gráfico de pizza) e a nota mais alta conquistada (gráfico de barras). Os alunos que tiveram os rendimentos mais altos (A04, A06, A07) são os mesmos que fizeram mais de uma tentativa na referida atividade, enquanto alguns dos demais (A02, A03, A05, A08 e A10) fizeram apenas uma tentativa ao longo do mesmo período. Enquanto alguns desses alunos que fizeram apenas uma tentativa (A08 e A10) conseguiram um aproveitamento superior a 70\%, outros não tiveram o mesmo êxito: os alunos A02, A03 e A05 não se deram a oportunidade de fazer mais tentativas e checar como estavam seus níveis de entendimento do assunto ao longo do período de vigência da atividade. 


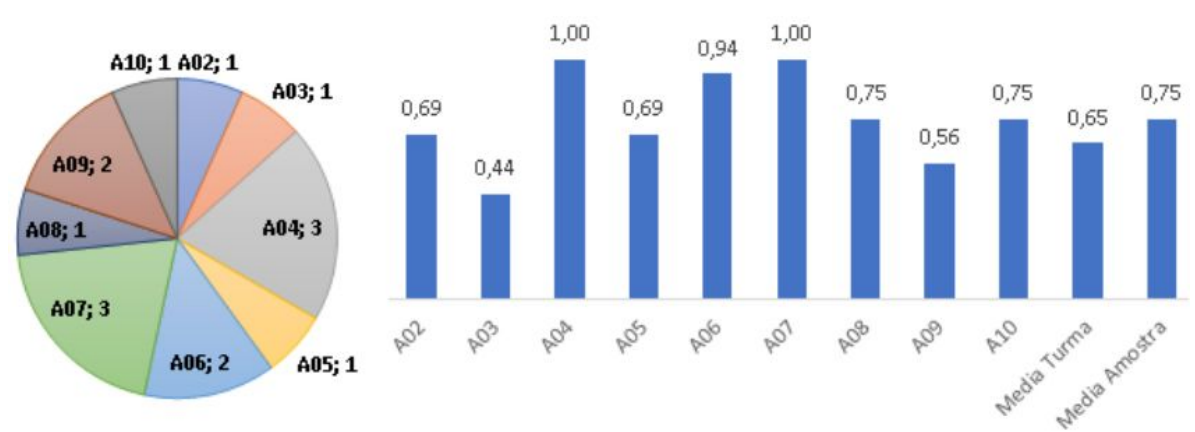

Figura 01. Total de tentativas e rendimento de 09 alunos na Atividade 5. Elaboração própria.

A Figura 02 apresenta o rendimento dos mesmos nove alunos em cinco atividades (Act01, Act02, Act03, Act04 e Act05) e uma prova ("Exam"), realizadas ao longo de 6 semanas. O empilhamento das barras também ilustra que quanto mais alta a pilha, mais pontos foram conquistados nas atividades. Nesse gráfico observa-se que alguns dos alunos (A06, A07 e A09) que apresentam as melhores notas na prova "Exam" também são alguns dos que conseguiram mais pontos nas atividades A01 a A05. Esses resultados, quando comparados com a Figura 01, por exemplo, permitem inferir que quanto mais esses alunos se dedicaram a fazer as atividades segundo o preconizado, melhor foram seus rendimentos acadêmicos.

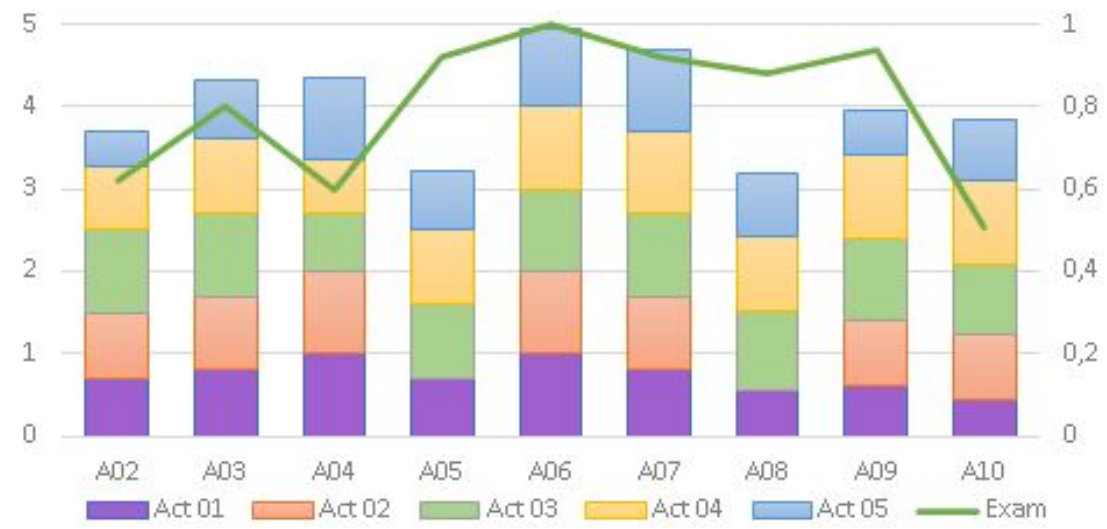

Figura 02. Rendimento de nove alunos em atividades e prova. Elaboração própria.

O contrário também mostra-se potencialmente verdadeiro: alguns alunos cuja quantidade de tentativas na Atividade 05 foram os mais baixos (A02, A10) são também aqueles que tiveram rendimento abaixo da média $(0,7)$ na avaliação "Exam". Isso permite inferir que talvez esses indivíduos não façam as atividades como preconizado, de forma a não se darem oportunidades de melhorar seus entendimentos sobre os assuntos estudados, o que possivelmente reflete no resultado de suas provas ser abaixo da média 0,7 .

Enquanto os alunos que fazem atividades ativamente são, em sua maioria, os que têm melhor rendimento (A06, A07, A09), alguns mostram um comportamento oportunista: fazem poucas ou apenas uma tentativa e obtém resultados satisfatórios, acima de $70 \%$ de aproveitamento, tanto nas atividades quanto nas avaliações (A03, A05, A08). Há também quem faça poucos exercícios (tentativas de atividades) e que tenha rendimento baixo (A02 e A10), e aqueles que até têm um rendimento alto nas 
atividades, mas que não apresentam um bom resultado na prova "Exam" (A04, A10), demonstrando dificuldade para melhorar seus rendimentos apesar de seus esforços.

Esses dados sobre o rendimentos dos alunos nas atividades, quantidade de tentativas que realizam e resultado na avaliação permite traçar perfis diferentes com relação a como se comportam, possibilitando à professora fazer intervenções a fim de auxiliar na mudança de comportamento e de estratégias de estudo a fim de favorecer seus processos de aprendizagem.

\section{Consideracoes Finais.}

A integração de tecnologias nos processos de ensino-aprendizagem vem assumindo relevante papel na educação, com destaque aos anos iniciais do Ensino Fundamental, dado o potencial de contribuição da sua utilização (KAMINSKI e BOSCARIOLI, 2016). Dessa forma, a experiência aqui relatada busca apresentar uma forma inovadora de se utilizar o AVA Moodle para o acompanhamento pedagógico de alunos em tempo real, à medida em que estes realizam atividades. Esse tipo de iniciativa tem se mostrado promissor no que tange à implicação do aluno em seu processo de aprendizagem, por possibilitar o pronto feedback após a realização de atividades no ambiente virtual, balizando e potencialmente a apropriação dos educandos pelo conteúdo a ser trabalhado.

Implicar o aluno no processo de aprendizagem significa, cada vez mais, disponibilizar e compartilhar informação sobre como utilizar os recursos disponíveis, sejam eles digitais ou não, para transformar dados em informação e, com a prática, desenvolver habilidades e conhecimento.

\section{Referências}

BARBOSA, G.; OLIVEIRA, E.; PENNA, J. 2015. Apreciação da Usabilidade do Moodle: Um Estudo de Caso no Contexto do Ensino Fundamental. Simpósio Brasileiro de Informática na Educação - SBIE, v. 26, n. 1, p. 712, 26 out.

KAMINSKI, M.; BOSCARIOLI, C. 2016. Uso do Moodle como estímulo aos estudos extraclasse no Ensino Fundamental: Uma experiência com o 5o Ano. Anais do Workshop de Informática na Escola, v. 22, n. 1, p. 535, 7 nov.

MELO FILHO, I; CARVALHO, R; GOMES, A; PERRIS, P; RODRIGUES, R; FELICIANO, F. 2014. Análise comparativa da Usabilidade dos Ambientes de Gestão da Aprendizagem Amadeus e Moodle. Revista Brasileira de Informática na Educação. 22. 10.5753/RBIE.2014.22.01.107.

NASCIMENTO, M. G. do; OEIRAS, J. Y. Y. 2008. Atividades para competições escolares de matemática no ambiente Moodle. Anais do Workshop de Informática na Escola, v. 1, n. 1, 1 jan.

NUNES, C. B. M. P. 2019. Perfil dos professores que usam ferramentas digitais em uma escola da rede privada em Natal/RN. Revista Prometeu, Ano V, n. 1. 